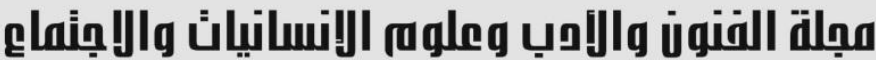

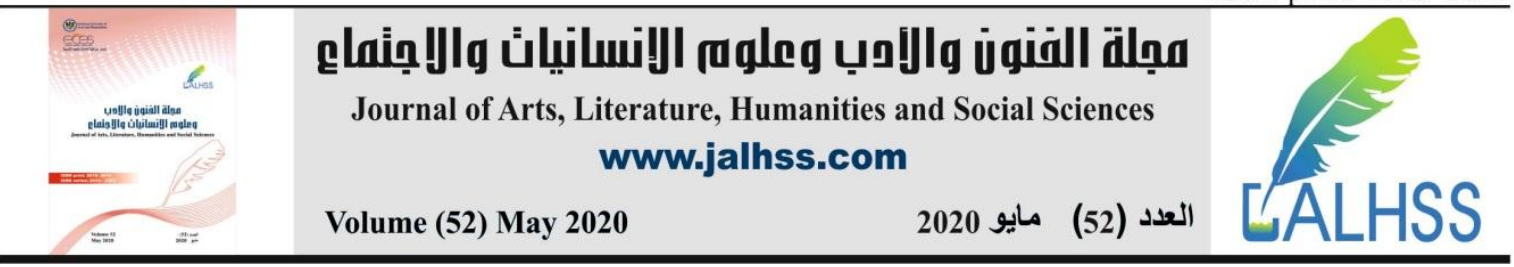

\section{جامع سيد سلطان علي واثرة في المجتمع البغدادي}

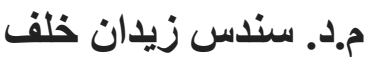
قسم العلوم الصرفة زئـ مركز إحياء التراث العلمي العربي ـ جامعة بغدادـ العراق الايميل:وundus.alshujayri@gmail.com

الملخص

مسجد من مساجد بغداد القديمة واقع على نهر دجلة المعلى قريب على مسجد الحاج نعمان في الجهة الثـرقية

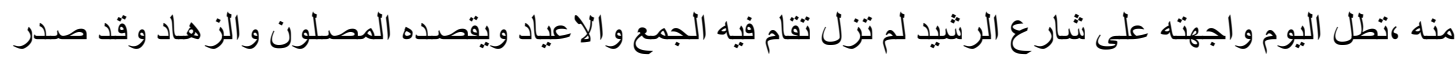
السلطان الغزي عبد الحميد خان ،بتجديد عمارته وتجديد بنيته و انثاء مدرستين وز اوية لاتباع ابي العلمين فتمت لهت

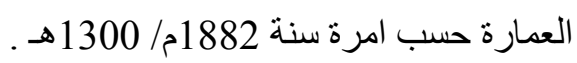
و لا يعرف تـاريخ أنشائه بالتحديد ويرجع البعض بنائه الى العصر العباسي ،وقد اختلف المؤرخون في نسب المرقد الثريف الذي اقيم عليه الجامع فالبعض يرجعه الى السيد علي بن الرفاعي و البعض الاخر ينسب المرقد

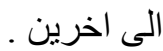
تطلب موضوع البحث تقسيمه الى ثلاثنة مباحث ،المبحث الاول يتحدث عن موقع وتاريخ وعمارة الجامع ، امـا المبحث الثاني : الحياة الفكرية في الجامع يتكلم عن مدرستي الجامع ومن درس فيها ،و التكية الرفاعية و المبحث الاخير : الاثر الاجتماعي للجامع في المجتمع العر اقي وبيان رواد المجالس التي تعقد في الجامع مـع دور الجامع في الحياة البغدادية .

الكلمات المفتاحية: جامع سيد سلطان علي، مساجد بغداد، الحياة البغدادية، المجتمع البغدادي. 


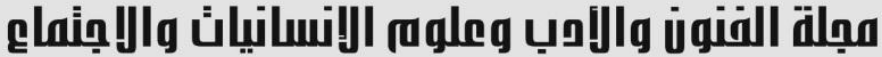
Journal of Arts, Literature, Humanities and Social Sciences

\section{Sayed Sultan Ali Mosque and its Impact on AL-Baghdadi Society}

\author{
Dr.Sandas Zidan Khalaf \\ Department of Pure Sciences - Center for the Revival of the Arab Scientific Heritage \\ University of Baghdad - Iraq \\ Emil: sundus.alshujayri@gmail.com
}

\section{ABSTRACT}

One of the mosques of old Baghdad is located on the Tigris River, the closest to the Hajj Numan Mosque on the eastern side of it, today it faces its façade on Al-Rashid Street. To follow Abi Al-Alamein, the building was completed according to the order of $1882 \mathrm{AH} / 1300 \mathrm{AH}$.

The exact date of its establishment is not known, and some refer to its construction as the Abbasid era. Historians have disagreed about the lineage of the Holy Shrine on which the mosque was built, some refer it to Sayyid Ali bin Al-Rifa'i, and others attribute the shrine to others.

The topic of the research required a division into three sections, the first topic talks about the location, history and architecture of the mosque, while the second topic: intellectual life in the mosque talks about my mosque's school and who studied there, and Al-Rafa'i hospice and the last topic: the social impact of the mosque in Iraqi society and the statement of the leaders of the councils held in The mosque with the role of the mosque in Baghdad's life.

Keywords: Mosque of Sayyid Sultan Ali, Mosques in Baghdad, Baghdad's life, Baghdad's community. 


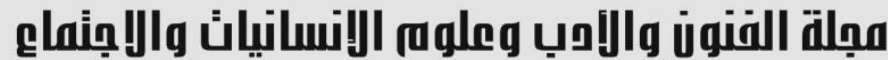

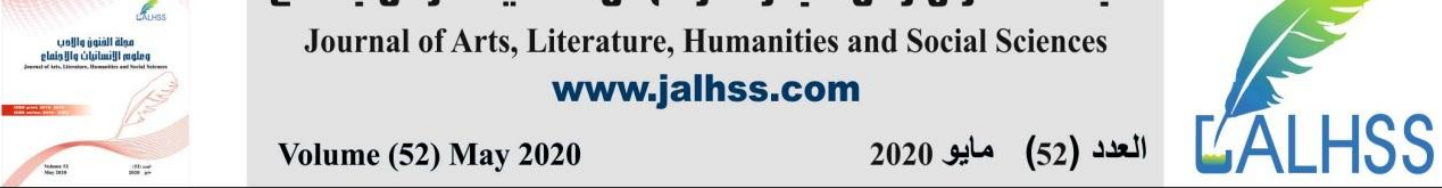

\section{المقدمة}

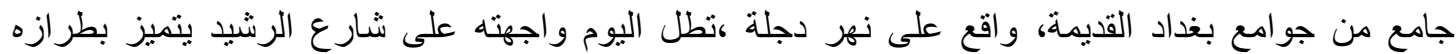

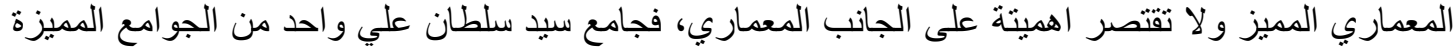

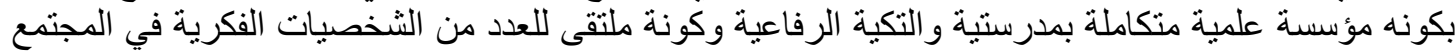

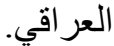

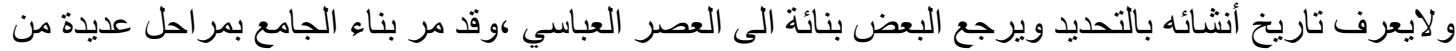

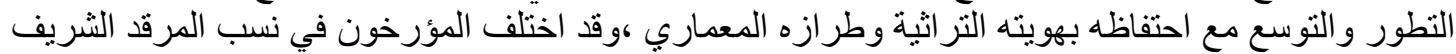

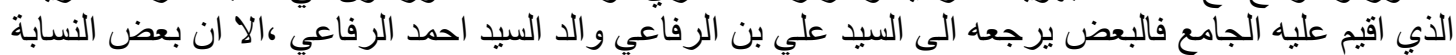
يشكلك في ذلك.

تطلب موضوع البحث تقسيمة الى ثلاثة مباحث ، المبحث الاول يتحدث عن موقع وتاريخ و عمارة الجامع ، اما

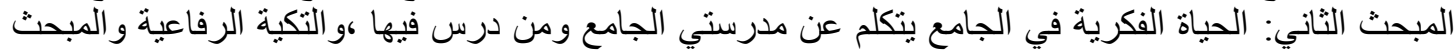
الاخير: الاثر الاجتماعي للجامع في المجتمع العر اقي وبيان رواد المئي المالس التي تعقد في الجامع مع دور الجامع

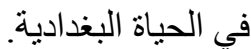
نظر لا تساع الموضوع تطلب من الباحثة الاستعانة بعدد من المصادر و المر اجع.

\section{المبحث الاول: موقع وتاريخ وعمارة الجامع

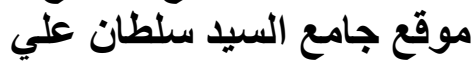

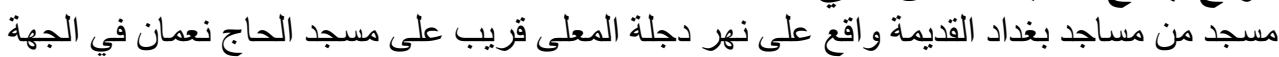

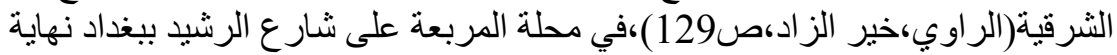

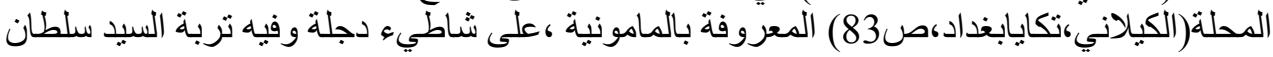

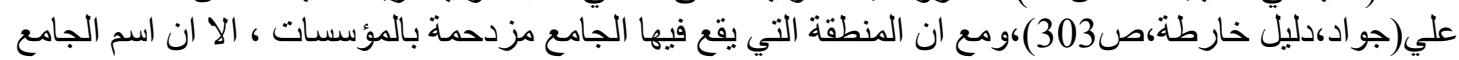

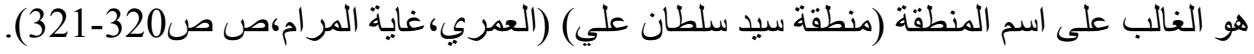

المراقد الموجودة في الجامع

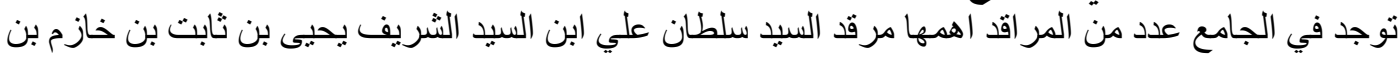

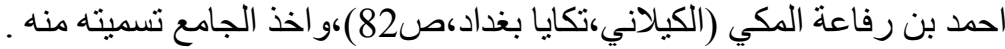

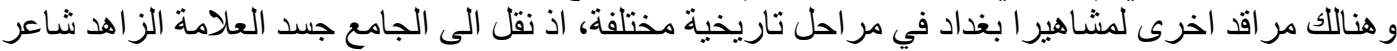

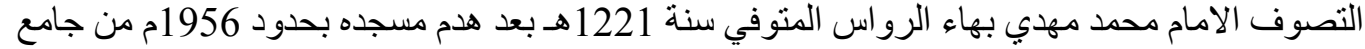

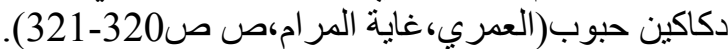

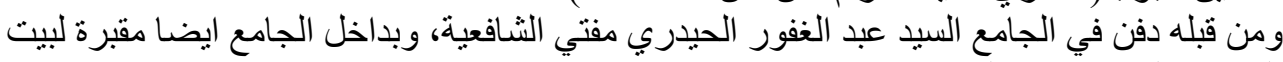

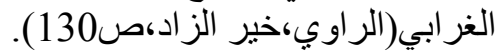

\footnotetext{
نسب السيا سلطان علي ونظر اللالتصاق اسم الجامع باسم صاحب المرقد وكونه اول من دفن فيه كان لابد لنا من الولوج في في شخصية

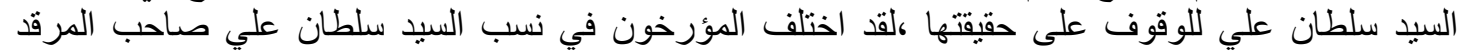

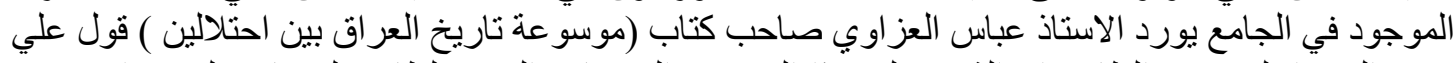

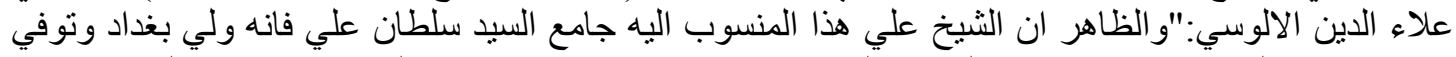

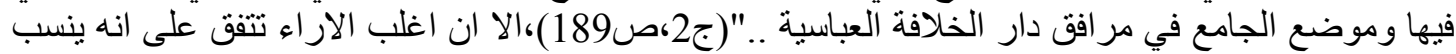

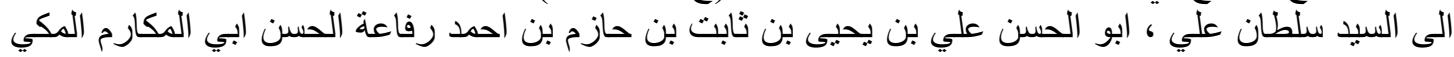

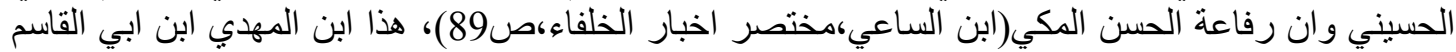

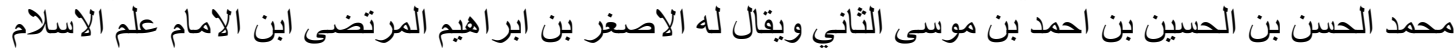

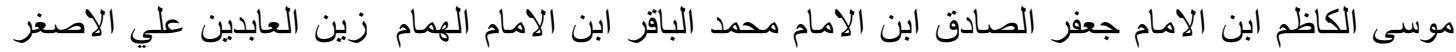




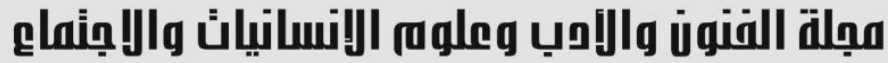

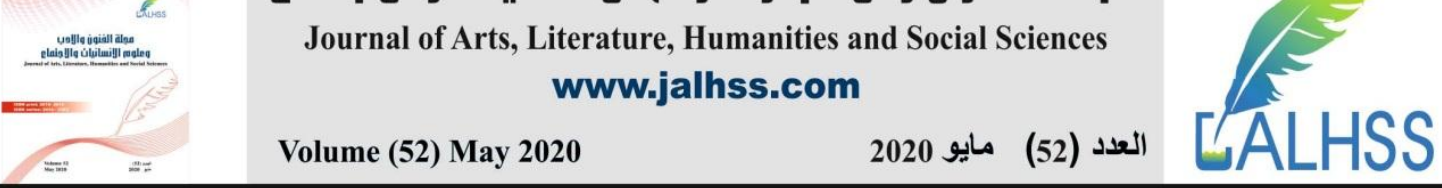

المعروف بالسجاد ابن الامام الثهيد السعيد السبط الاعظم ابي عبد الله الحسين الثهيد بكربلاء ابن الامام الاعظم

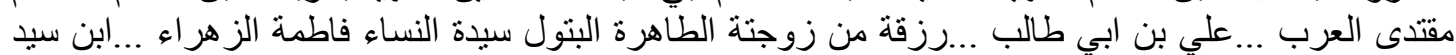

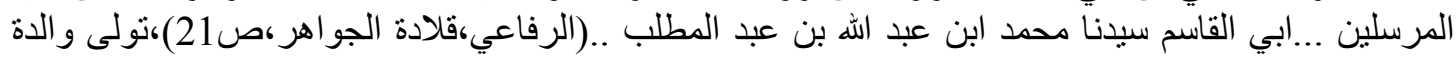

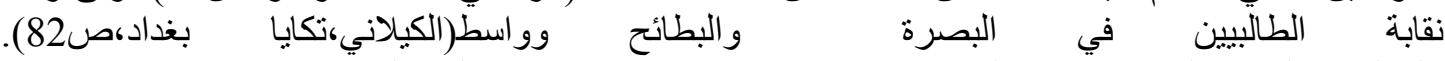

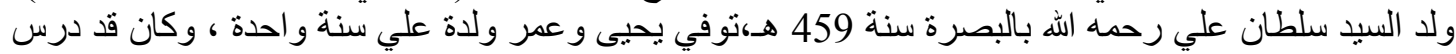

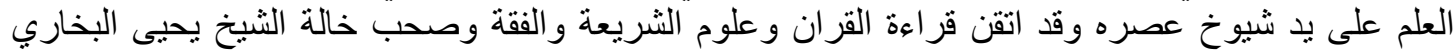

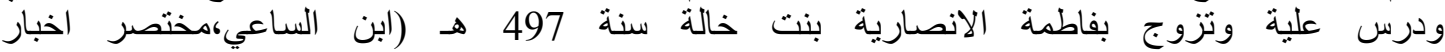

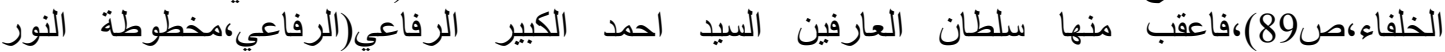

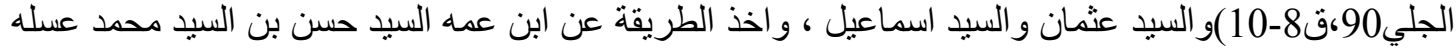

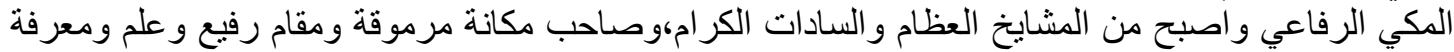

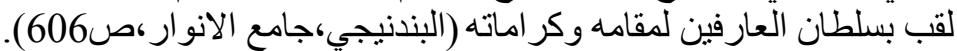

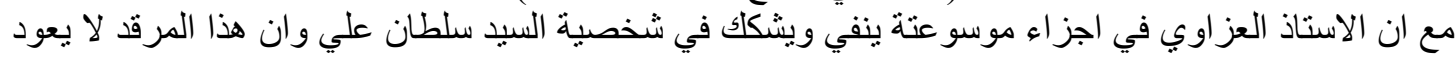

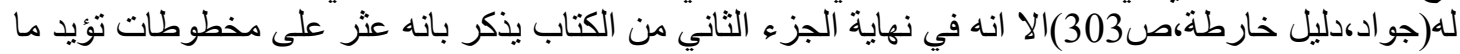

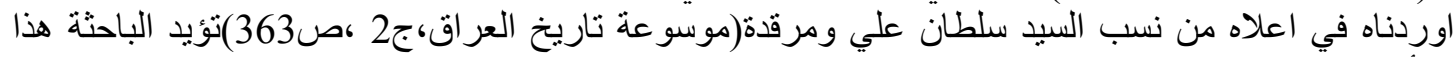

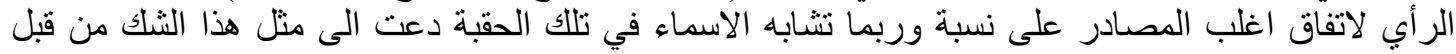

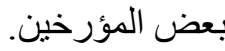

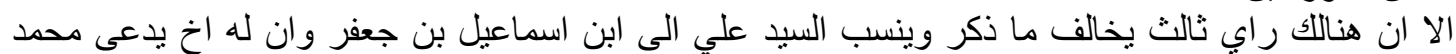

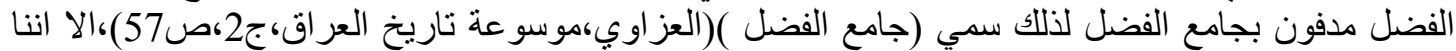

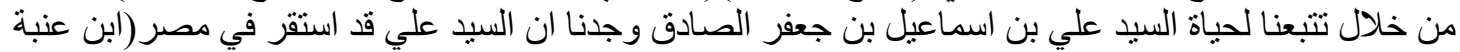

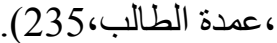

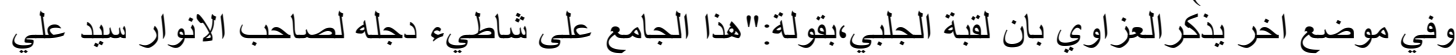

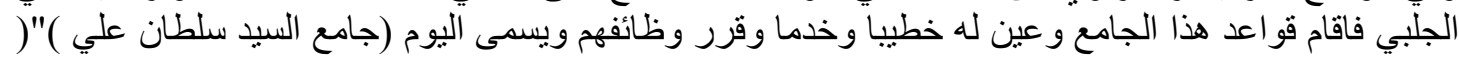

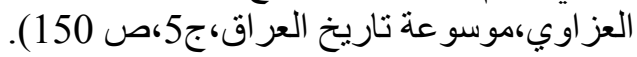

بناء الجامع ن باريخ

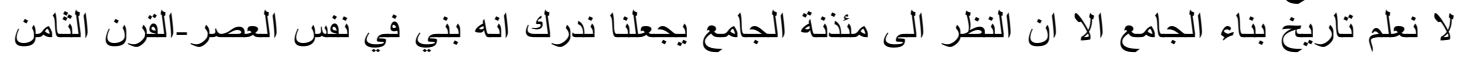

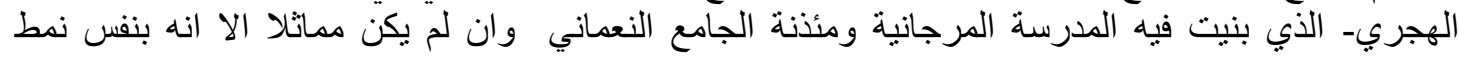

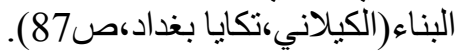

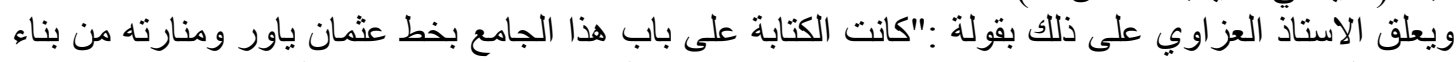

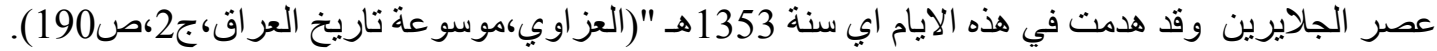

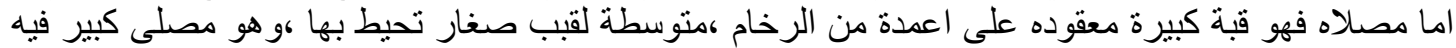

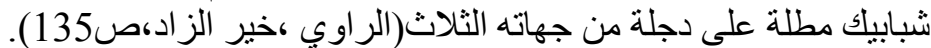

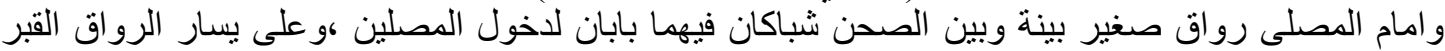

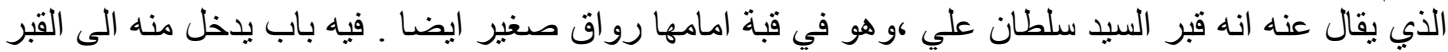

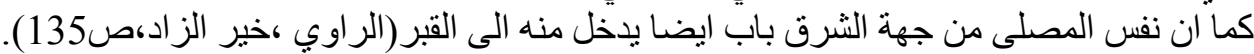

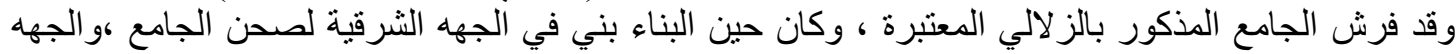

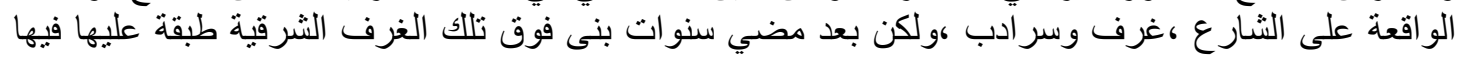

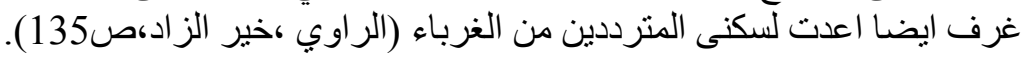

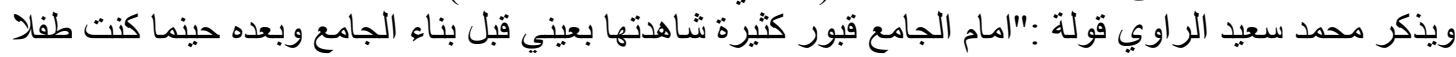

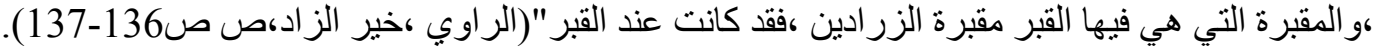

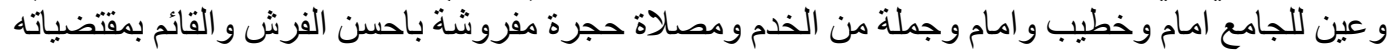
ادارة الاوقاف المحلية(الالوسي،تاريخ مساجد بغداد، 41). 


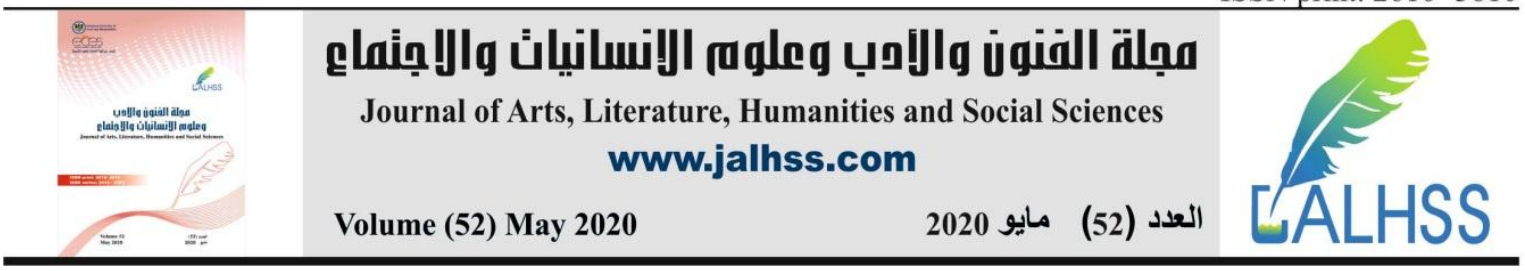

اما القائم بادارته مع رو اتب الموظفين و اطعام الزوار و الغرباء فهي دائرة الاوقاف وقد خصص الفي للاطعام ايضا

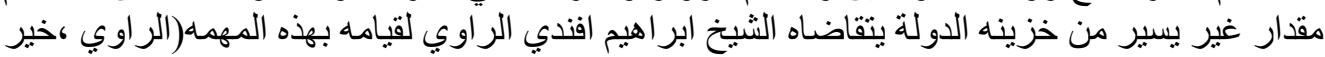

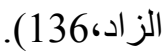

$$
\begin{aligned}
& \text { تجديا وتوسعة بناء الجامع }
\end{aligned}
$$

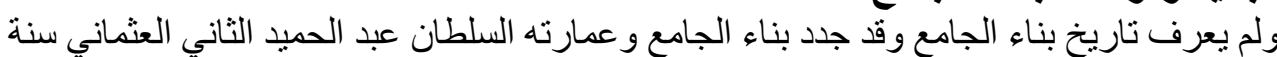

$$
\begin{aligned}
& \text { 1310هـ/1813م(السامر ائي،تاريخ مساجد بغداد، 45). }
\end{aligned}
$$

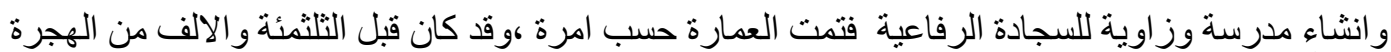

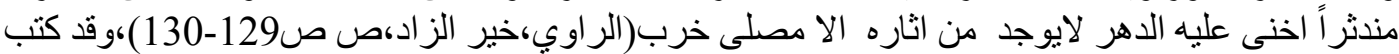

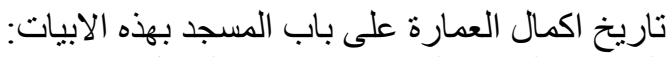

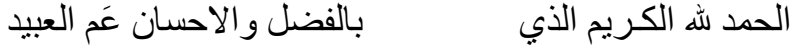

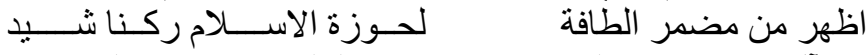

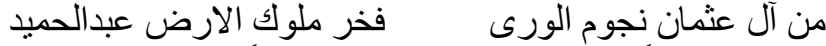

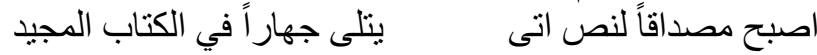

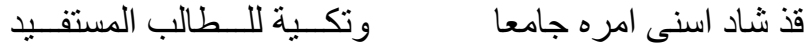

$$
\begin{aligned}
& \text { وحولة مدرستان ابتنى و المرقد السامي الثريف السعيد }
\end{aligned}
$$

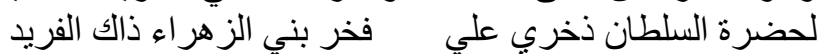

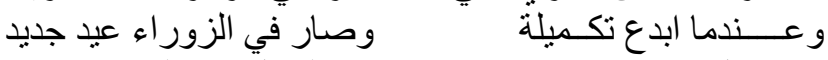

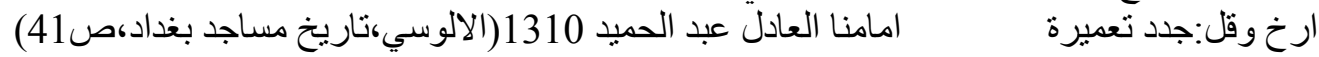

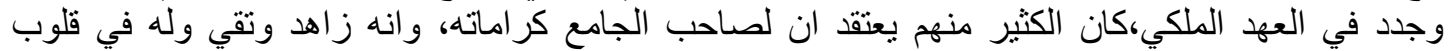

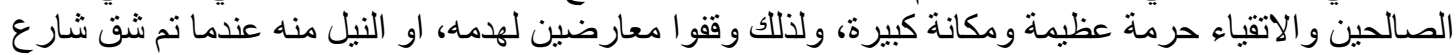

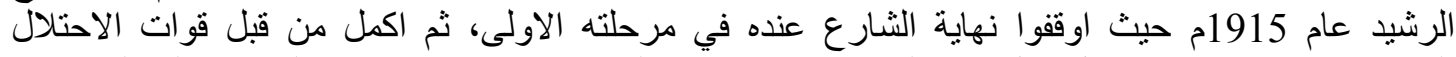

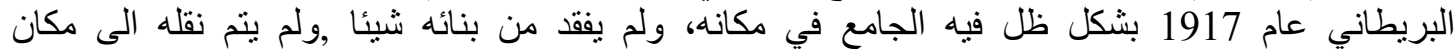

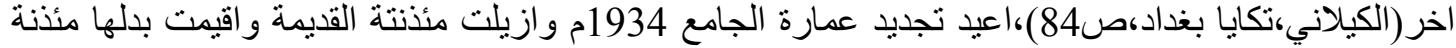

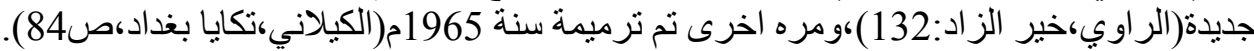

وتم توسعة في الثمانينات ،و اخرج بشكل جميل وصارت توليتة بيد السيد رجب الر اوي الرفاعي،و اعيد تجديدة في

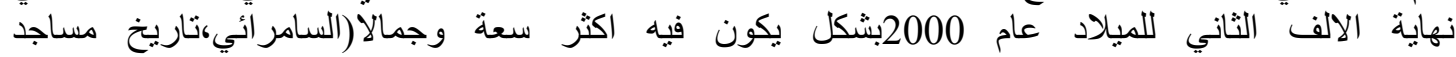

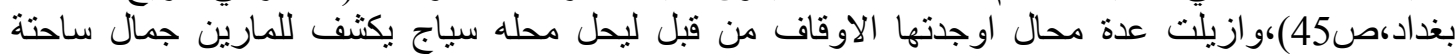

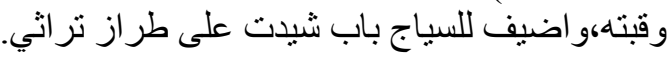

تم احداث تغير ات بغية توسعة الجامع مع الحفاظ على هو يتة التر اثية فقد وسع المصلى واضيف الية مصلى جديد

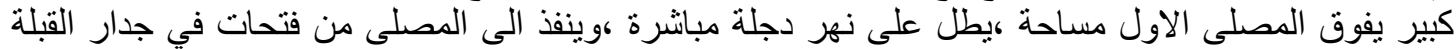

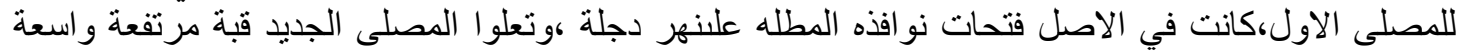

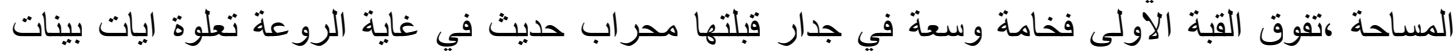

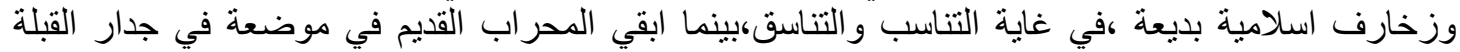

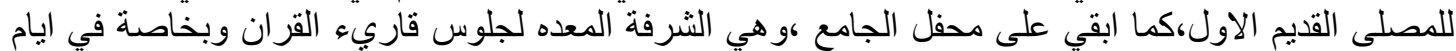

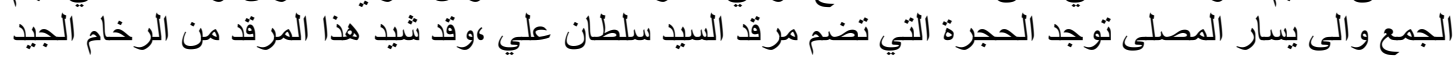

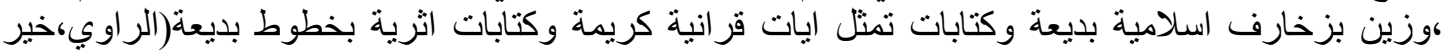




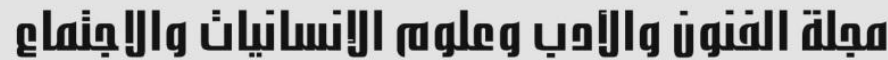

Journal of Arts, Literature, Humanities and Social Sciences
www.jalhss.com
$=$

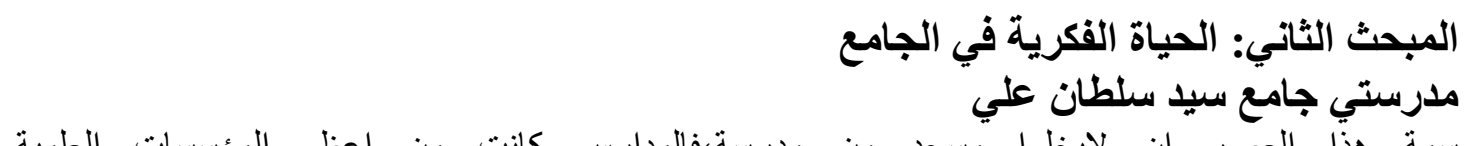

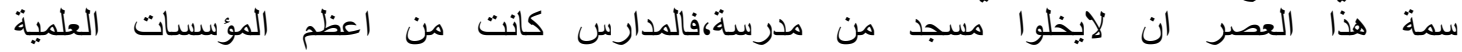

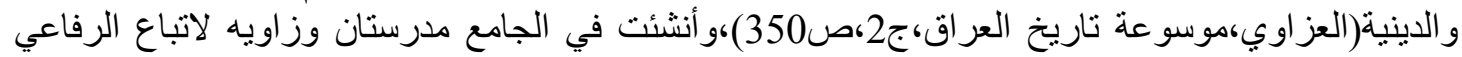

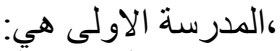

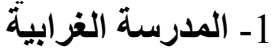

اوقف الحاج حسين افندي بن عبد الله الغرابي ،فوقف مدرسته الو اقعة على نهر دجلة باتصال جامع السيد سلطان

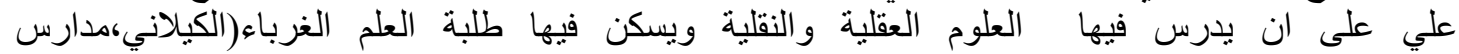

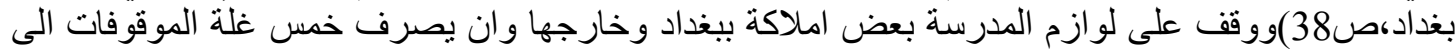

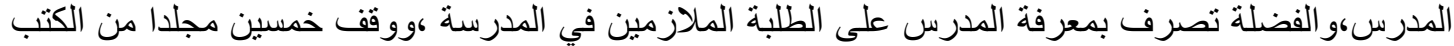

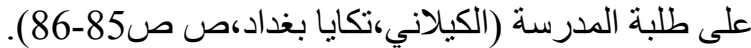

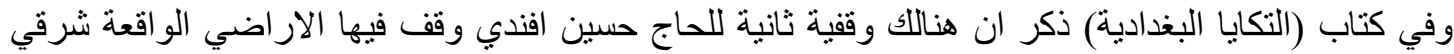

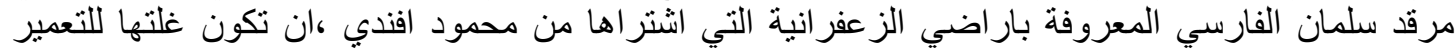

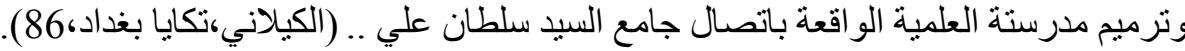

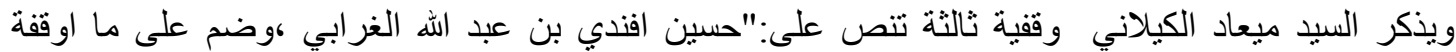

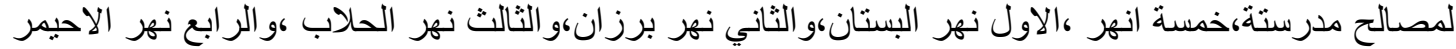

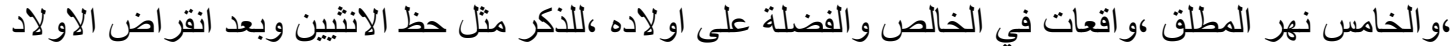

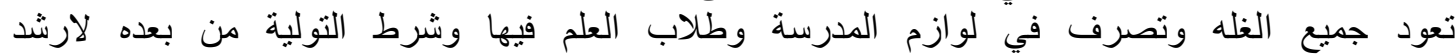

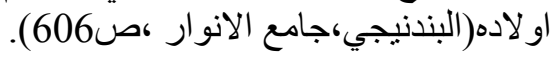

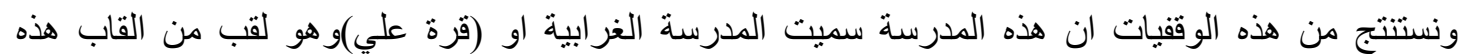

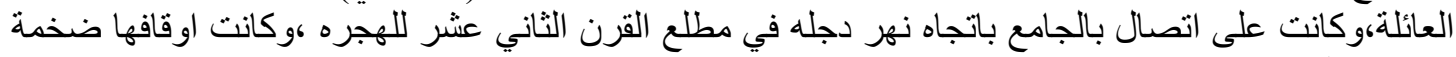

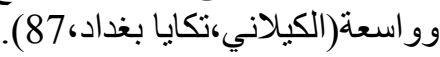

ويذكر الدروبي هذه المدرسة بقوله:"مدرسة حسين افندي الغرابي بن عبد الله مطلة على نهر دجلة وبابها على الى الى القي

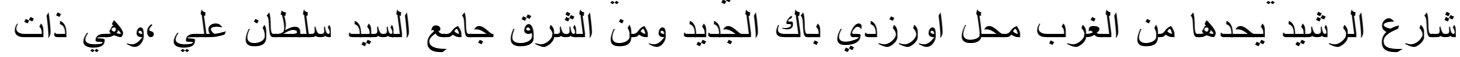

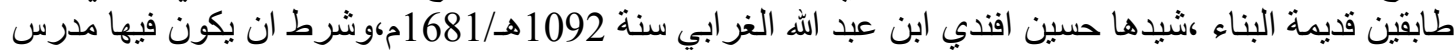

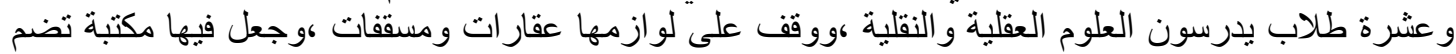

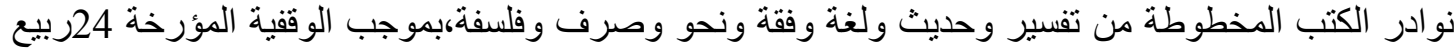

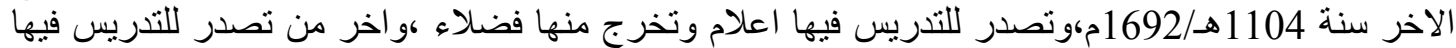

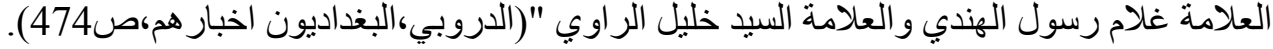

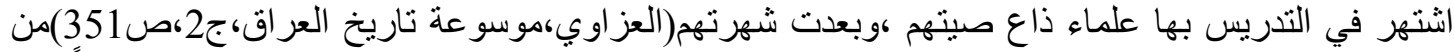

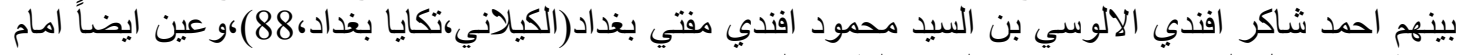

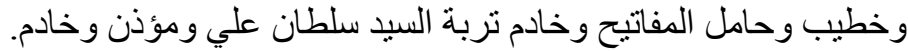

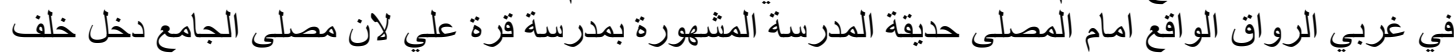

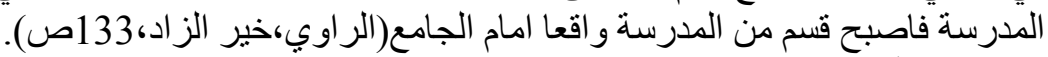

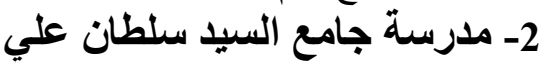

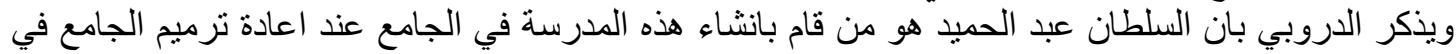

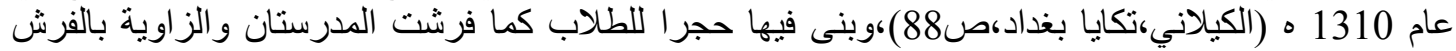

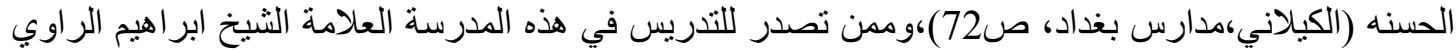




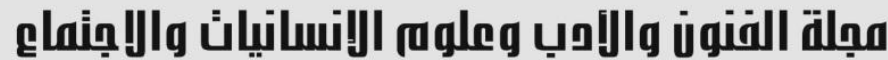

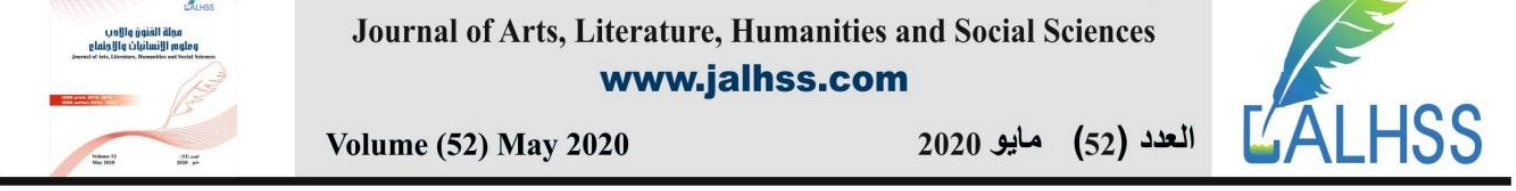

ومن بعده عين شكري افندي الالوسي ومحمود شكري الالوسي(الر اوي،خير الزاد:132-133)،وممن درس بها

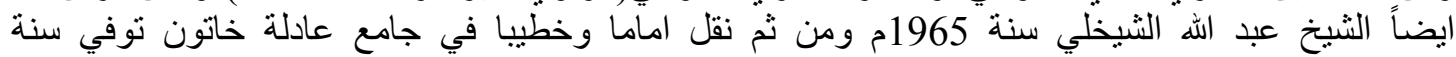

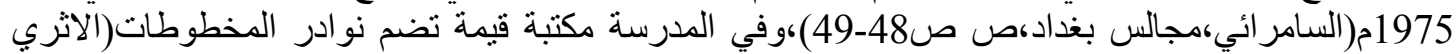

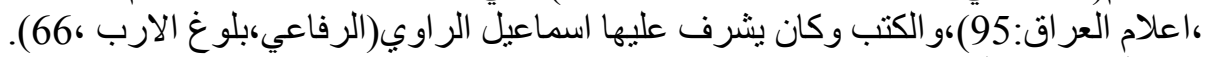

التكية الرفاعية

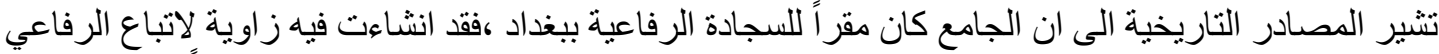

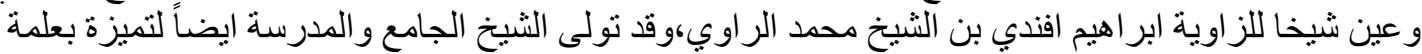

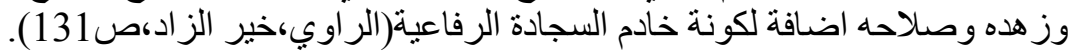

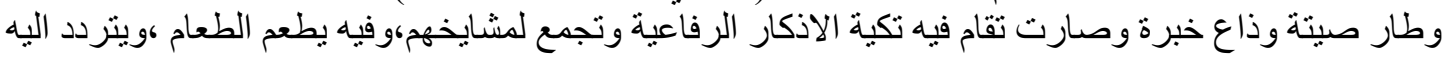

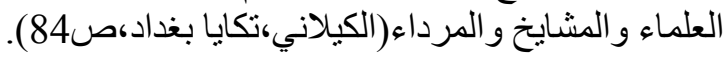

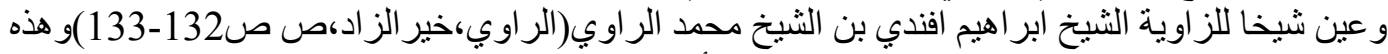

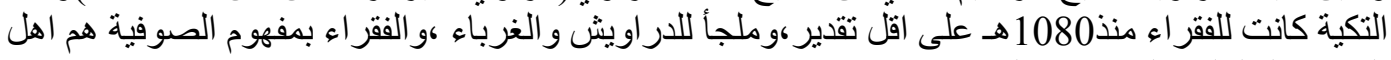

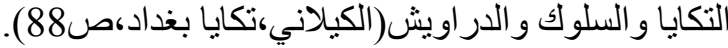

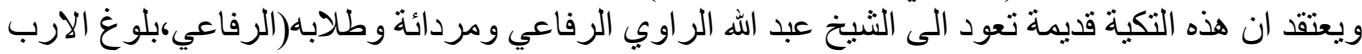

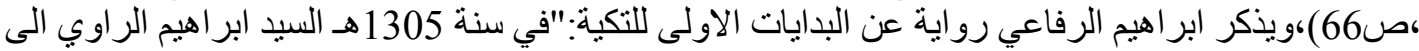

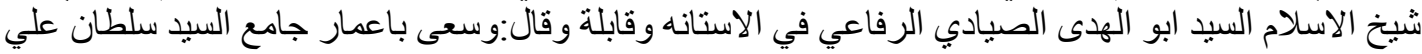

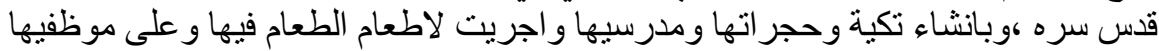

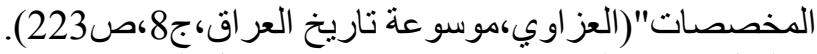

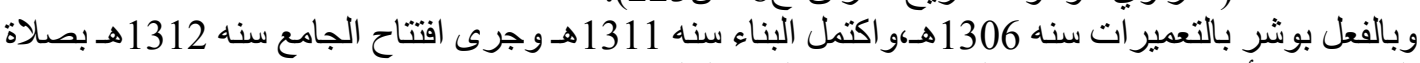

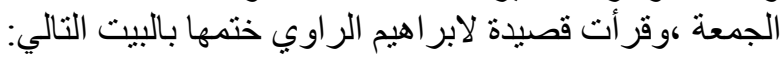

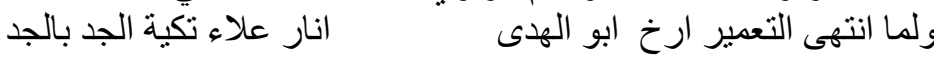

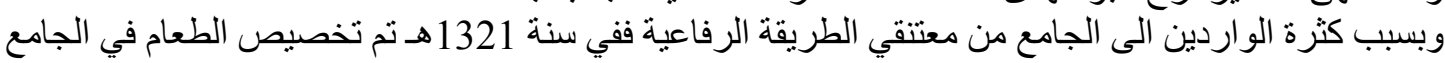

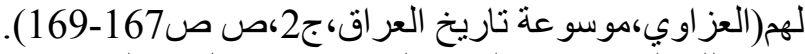

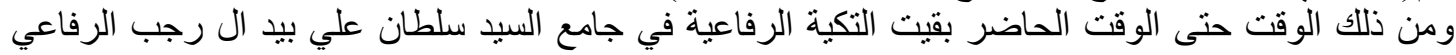

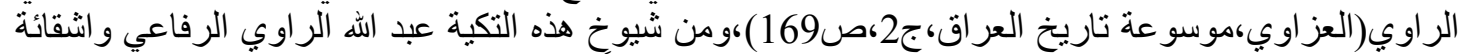

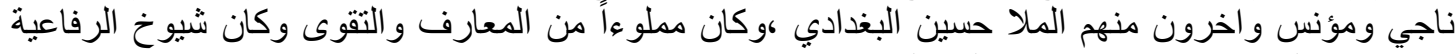

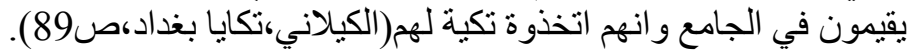

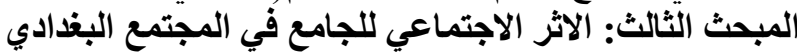

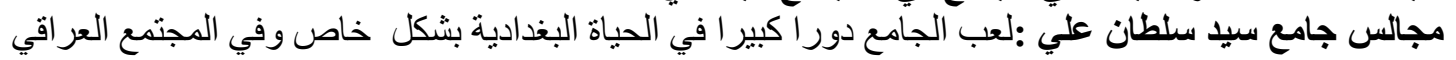

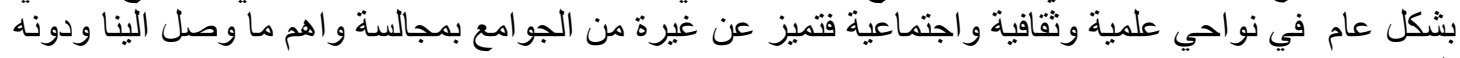
المؤرخون هي : مام في نو

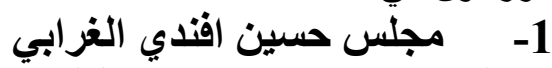
بيت الغرابي بيت قديم معروفت بالعلم والادب وابل والفضل عميد هذه الاسرة حسين بن عبد الله جلبي الغرابي

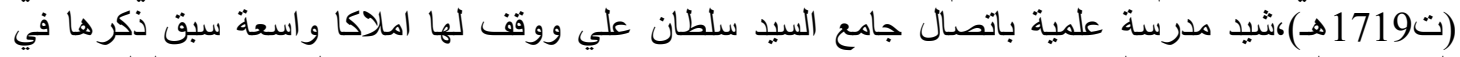

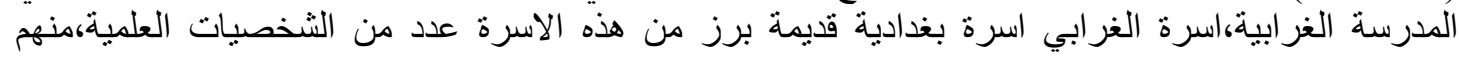

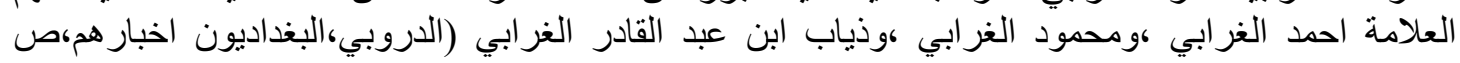

ص146-145). (146)

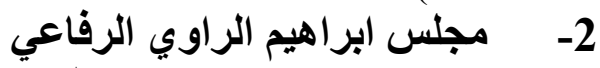

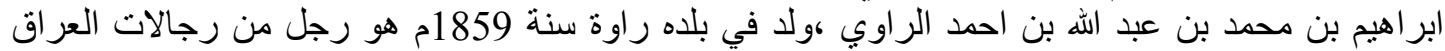

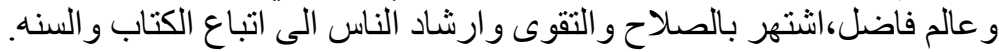

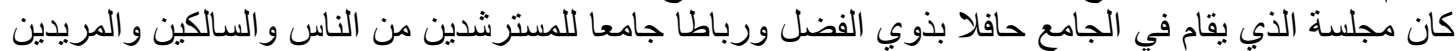

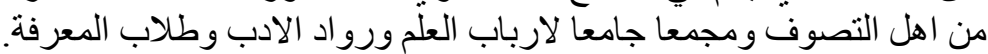




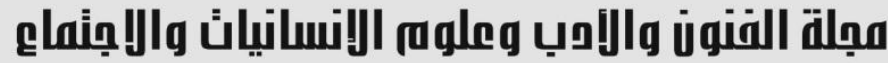

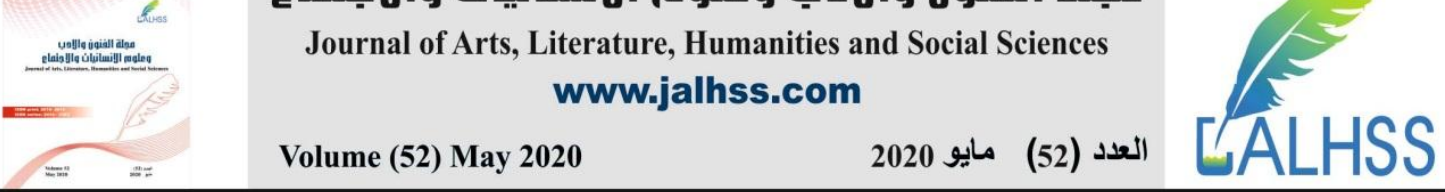

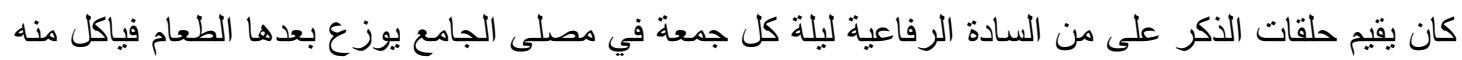

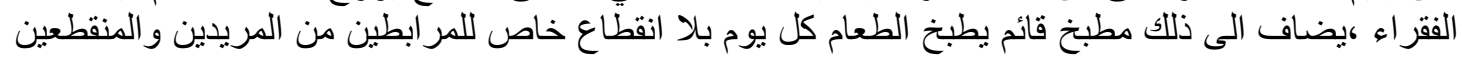

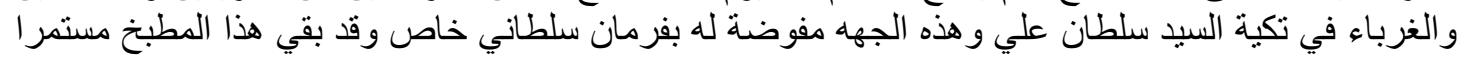

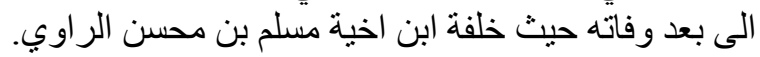

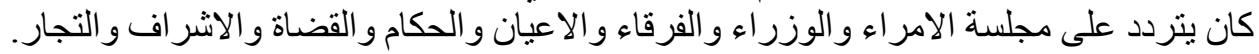

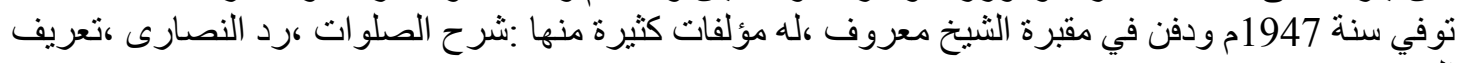

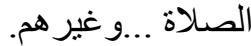
وقد خلفة لخدمة التكية خليل الراوي كان من خيار الناس ومن مدرسي الجامع وفي مدرسة حسين افندي الغرابي

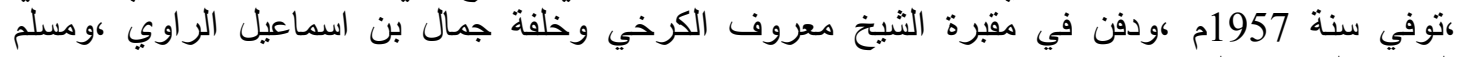

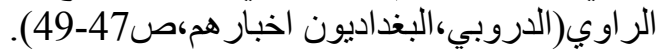

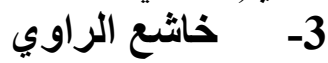

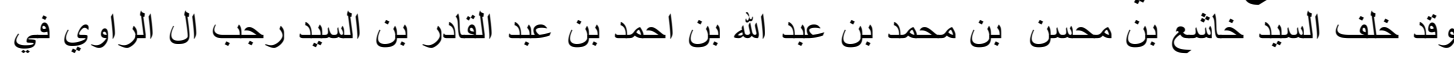

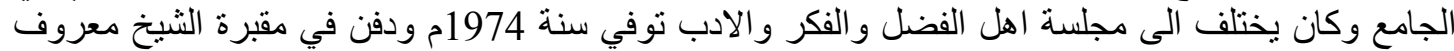

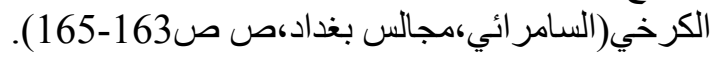

\section{الجامع في الحياة البغدادية}

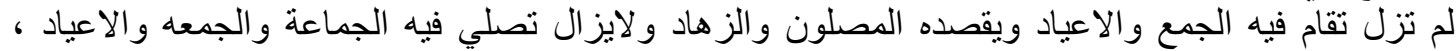

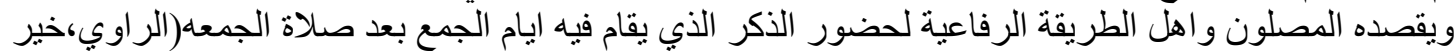
الزاد،ص131)،في القرن الحادي عشر تحول الى جامع كبير تقام فيه الصلوات الذئ الخمسة(الكيلاني،تكايا

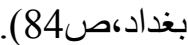
ويصفة السيد عباس البغدادي بقولة :"المسجد الذي فيه ضريح السيد علي وهو مسجد حافل معمور بالجمع

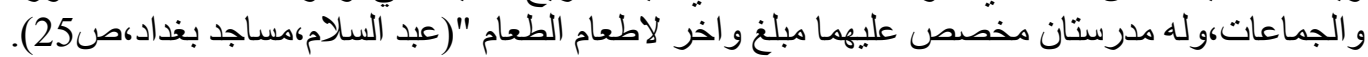

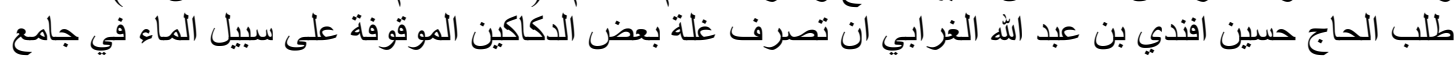

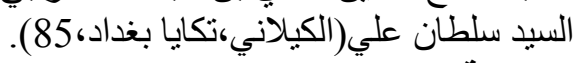

الخاتمة

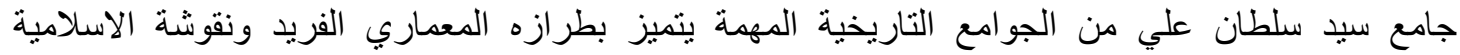

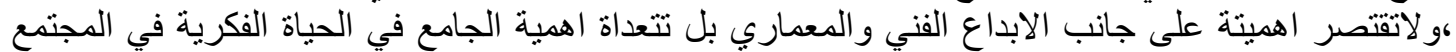

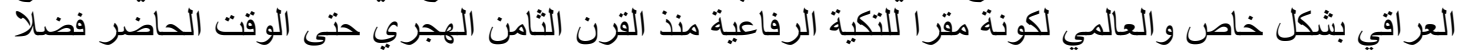

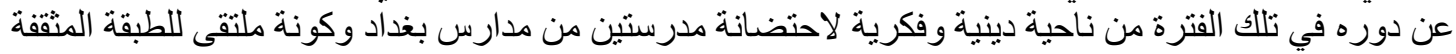

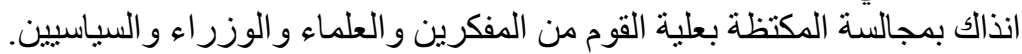




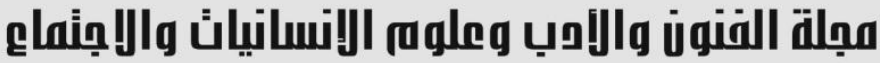

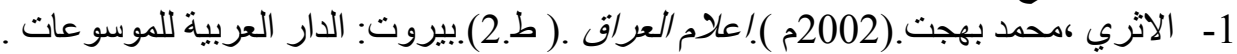

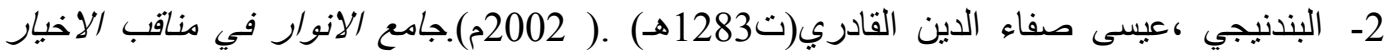

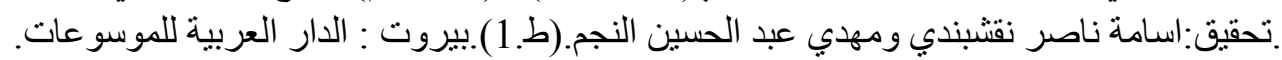

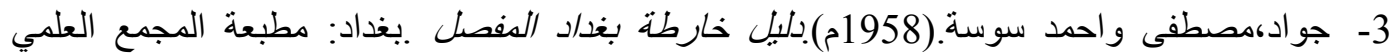

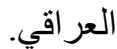

4- الدروبي، ابر اهيمة/لبغد/ديون اخبار هم ومجالسهم.(1958م). بغداد: مطبعة الر ابطة.

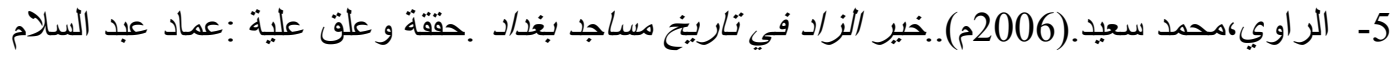

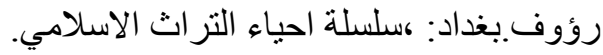

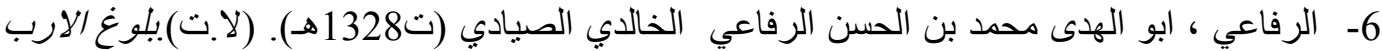

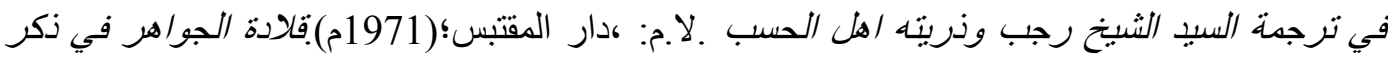

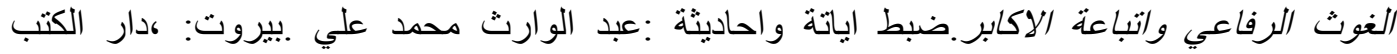

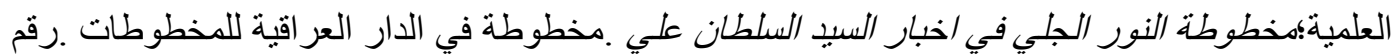
(90) (9بغداد. (9) 7- ابن الساعي ،تاج الدين علي بن انجب بن عثمان البغدادي (ت674هـ).(1309هـ).مختصر اخبار

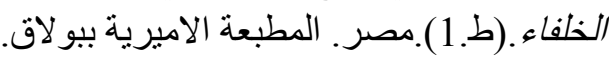

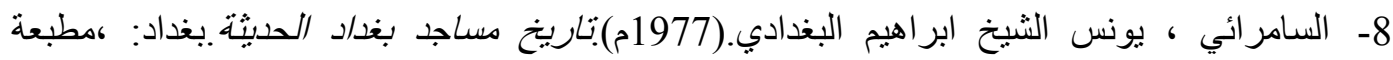

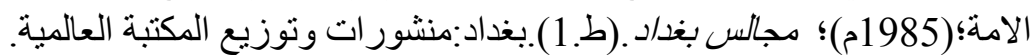

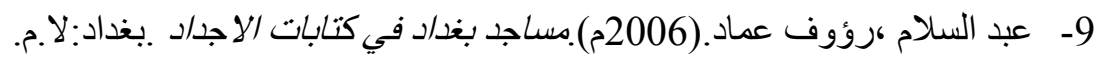

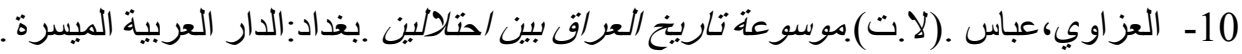

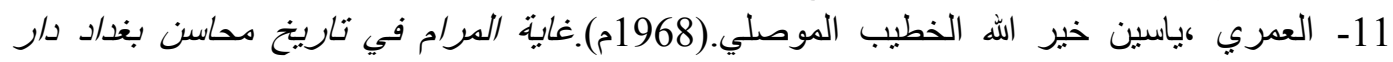

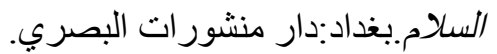

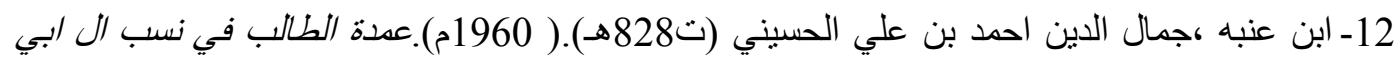

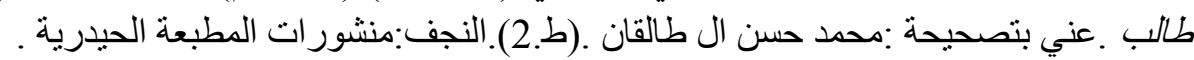

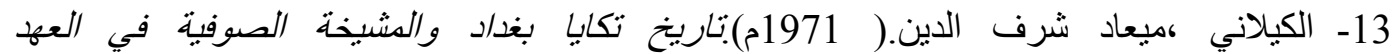

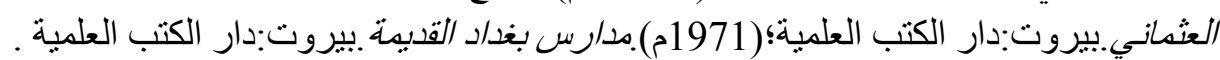

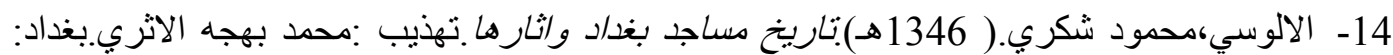
مطبعة دار السلام في بغداد. 


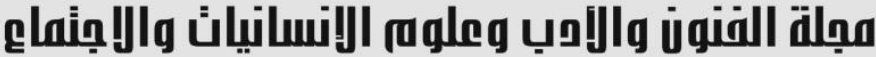

Journal of Arts, Literature, Humanities and Social Sciences

www.jalhss.com

Volume (52) May 2020

العدد (52) مايو 2020

\section{References}

1- Al-Athri, Muhammad Bahjat. (2002 AD), Iraq Flags (2nd edition). Beirut: The Arab Encyclopedia.

2- Al-Bandaniji, Issa Safa Al-Din Al-Qadiri (d. 1283 AH). (2002). Al-Anwar Mosque in the Venerables of the Good Men.

3- Jawad, Mustafa and Ahmed Sousse. (1958 AD). Baghdad road map detailed guide. Baghdad: Iraqi Academy Complex Press.

4- Al-Droubi, Ibrahim, Al-Baghdadi, their news and councils (1958 AD). Baghdad: Al-Rabta Press.

5- Al-Rawi, Muhammad Saeed. (2006 AD) .. Khair Al-Zad in the history of the Baghdad mosques. Truth and comment on him: Imad Abdul Salam Raouf. Baghdad: series of reviving Islamic heritage.

6- Al-Rifai, Abu al-Huda Muhammad ibn al-Hasan al-Rifai al-Khaldi al-Sayyadi (d. 1328 AH) (No. House of Scientific Books: The Clear Light Manuscript in the News of Sultan Sultan Ali. Manuscript in the Iraqi House of Manuscripts No. 90 in Baghdad.

7- Ibn al-Sa i, Taj al-Din Ali bin Angab bin Othman al-Baghdadi (d. 674 AH). (1309 AH). Brief news of the caliphs. (I. 1). Egypt. Al-Amiriya Printing Press, Bulaq.

8- Al-Samarrai, Younis Al-Sheikh Ibrahim Al-Baghdadi. (1977 AD). History of modern Baghdad mosques. Baghdad: The Nation Press; (1985 AD); Baghdad Councils.

9- Abdul Salam, Raouf Imad. (2006 AD). Baghdad mosques in ancestral writings. Baghdad: No. M.

10- Al-Azzawi, Abbas. (N.D). Encyclopedia of Iraqi History between two Occupations. Baghdad: The Facilitated Arab House.

11- Al-Omari, Yassin Khair Allah, Al-Khatib Al-Mawsali. (1968). The purpose of the Maram in the history of the virtues of Baghdad, Dar Al-Salam. Baghdad: AlBasri Publications House.

12- Ibn Enabah, Jamal al-Din Ahmad bin Ali al-Husayni (d. 828 AH) (1960 AD). The mayor of the student in the lineage of Abi Talib. I mean by correcting: Muhammad Hassan al-Talqan. (I.2). Al-Najaf: Publications of Al-Haidariyya Press. 13- Al-Kilani, the date of Sharaf al-Din. (1971). The history of Takaya of Baghdad and the Sufi sheikdom in the Ottoman period. Beirut: House of Scientific Books; (1971 AD). Old Baghdad schools. Beirut: House of Scientific Books. 14-Al-Alusi, Mahmoud Shukri. (1346 AH). History and effects of Baghdad's mosques. Refinement: Muhammad Bahjah Archaeological. Baghdad: Dar Al-Salam Press in Baghdad. 


\begin{tabular}{|c|c|c|c|}
\hline 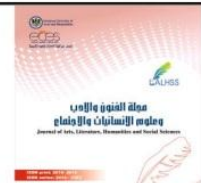 & 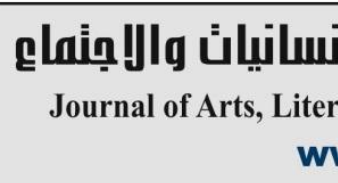 & 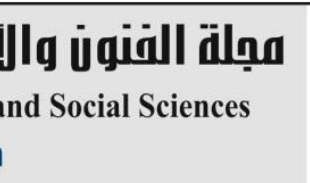 & \\
\hline$==$ & Volume (52) May 2020 & العدد (52) مايو 2020 & \\
\hline
\end{tabular}

ملحق الصور

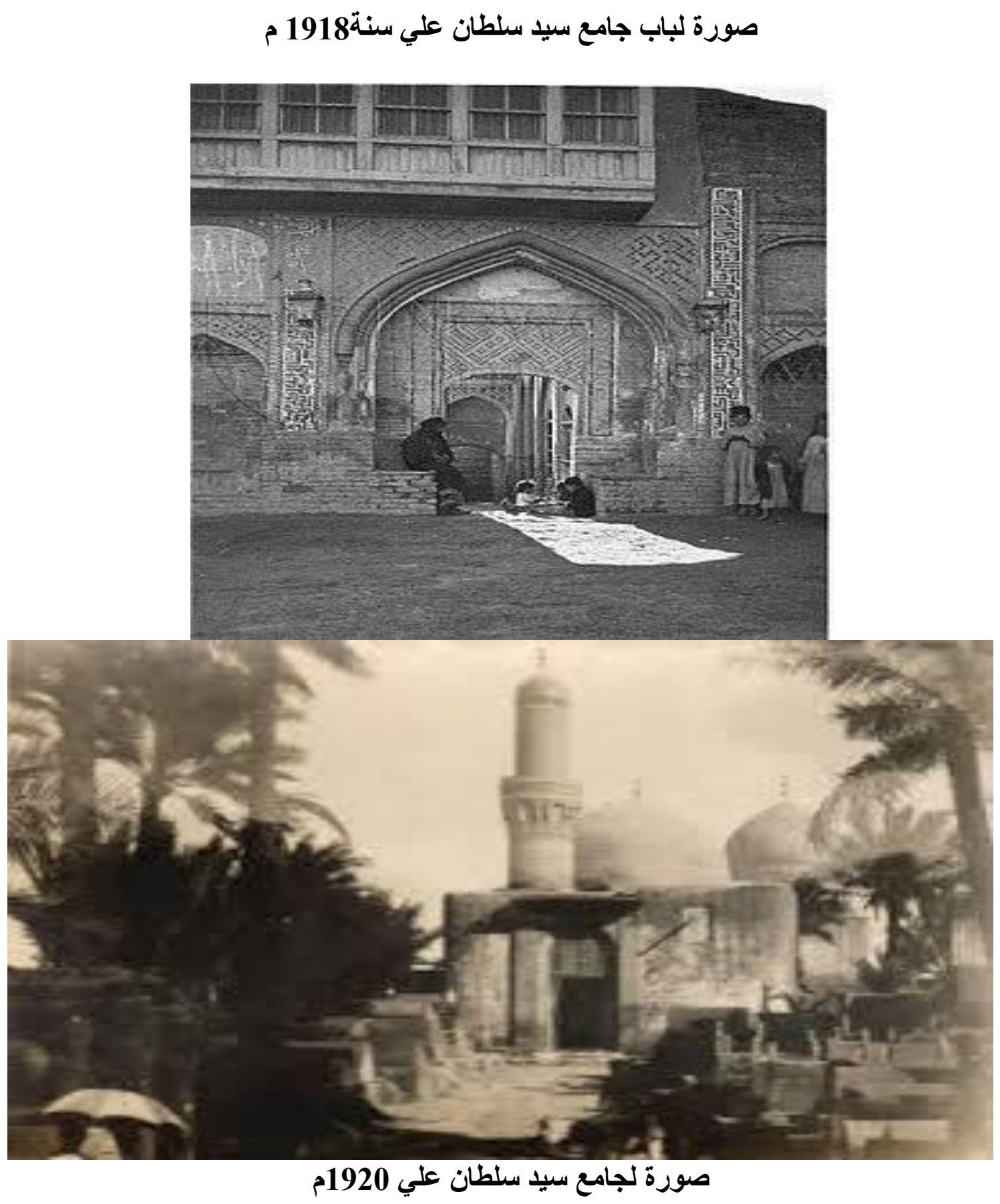




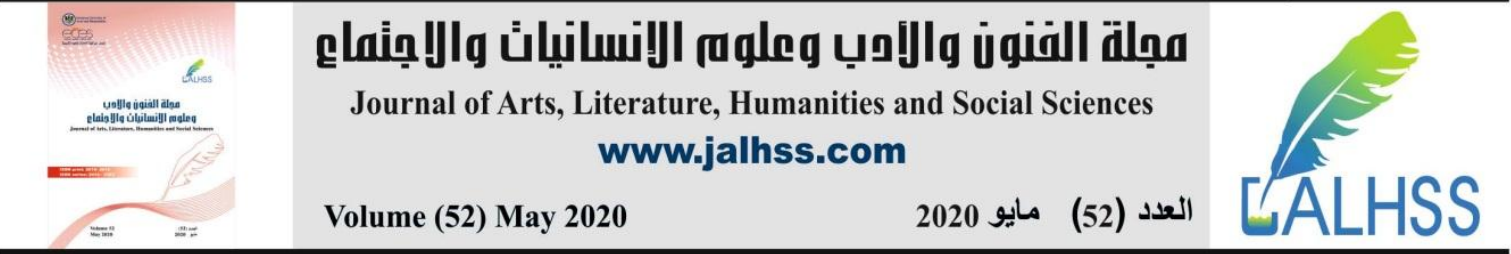

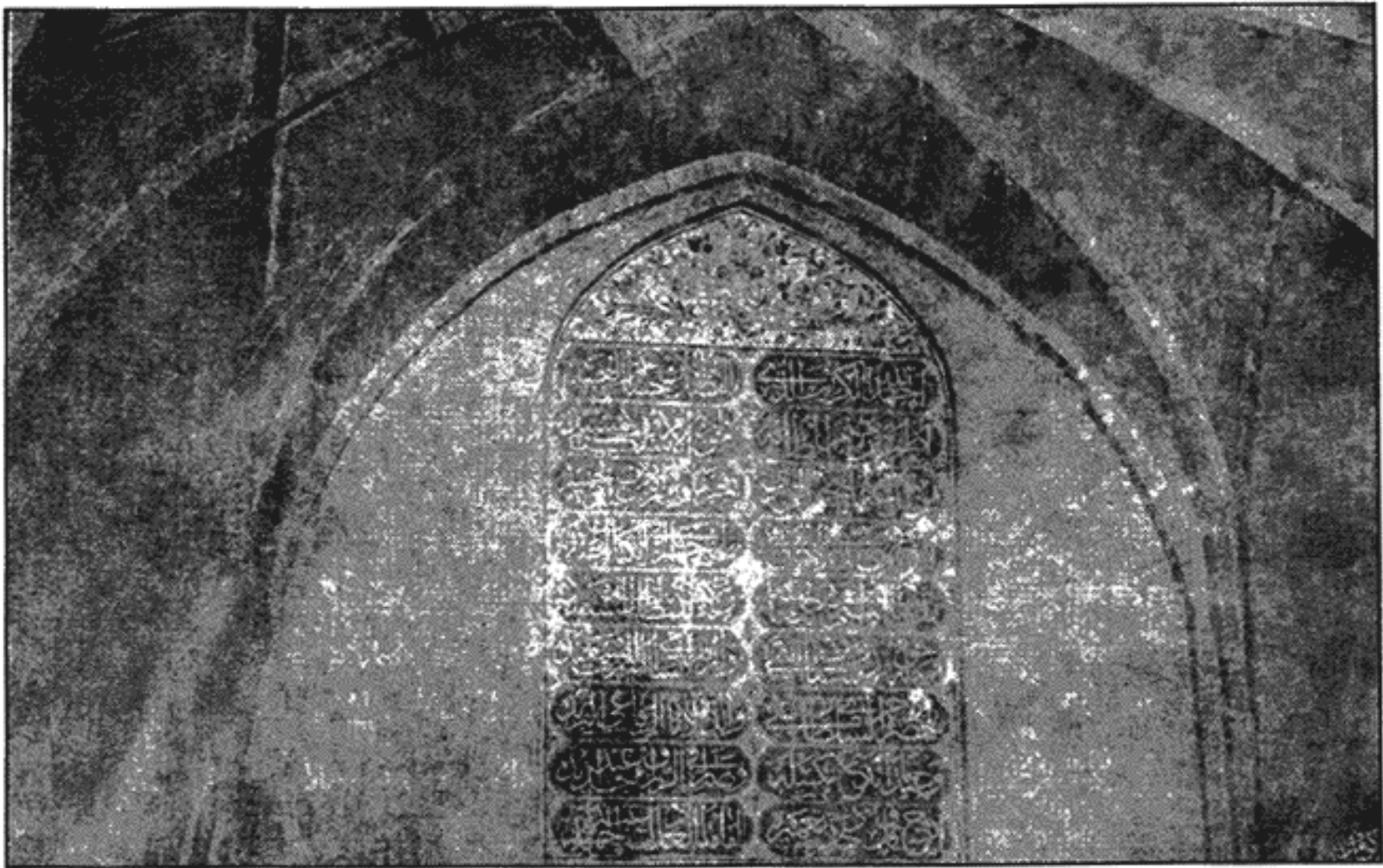

الكتابة فوق مذخل مرقد سيد سلطان علي ـ دال الآثار العراقية

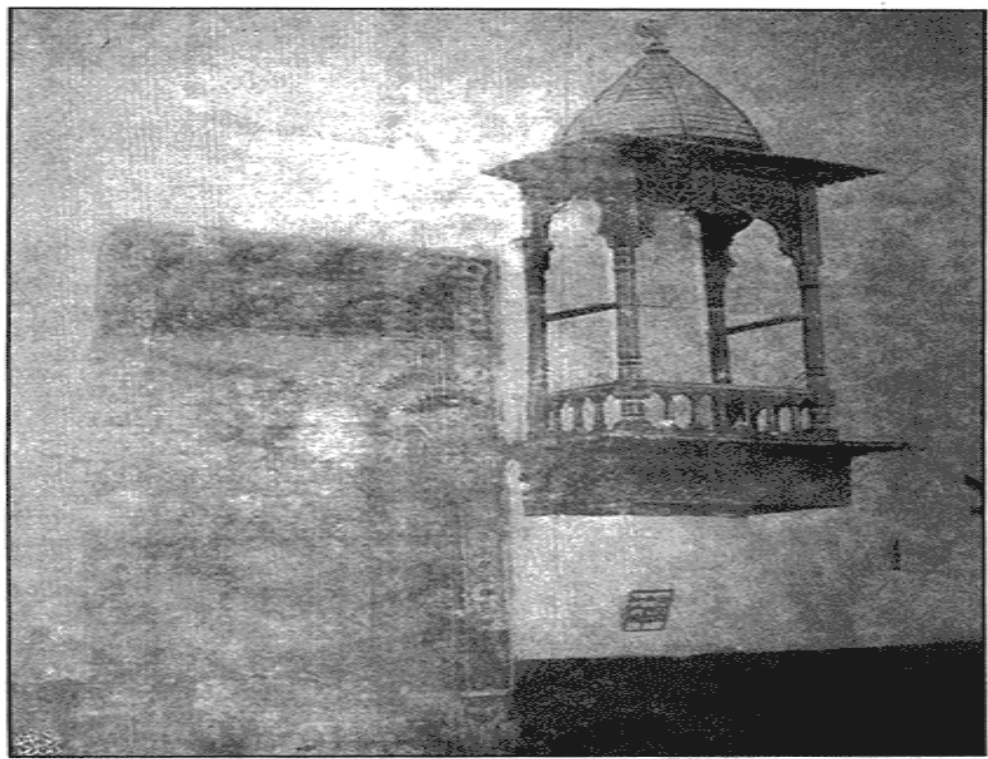

محراب ومنير جامع سيث سلطان علي - دار الآنار العراقيه 


\begin{tabular}{|c|c|c|c|}
\hline 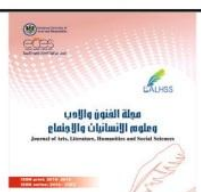 & 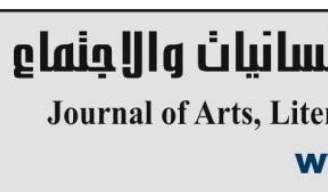 & 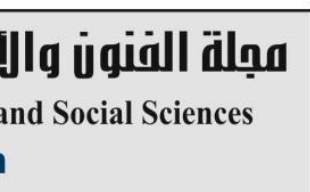 & \\
\hline$==$ & Volume (52) May 2020 & العدد (52) مايو 2020 & \\
\hline
\end{tabular}

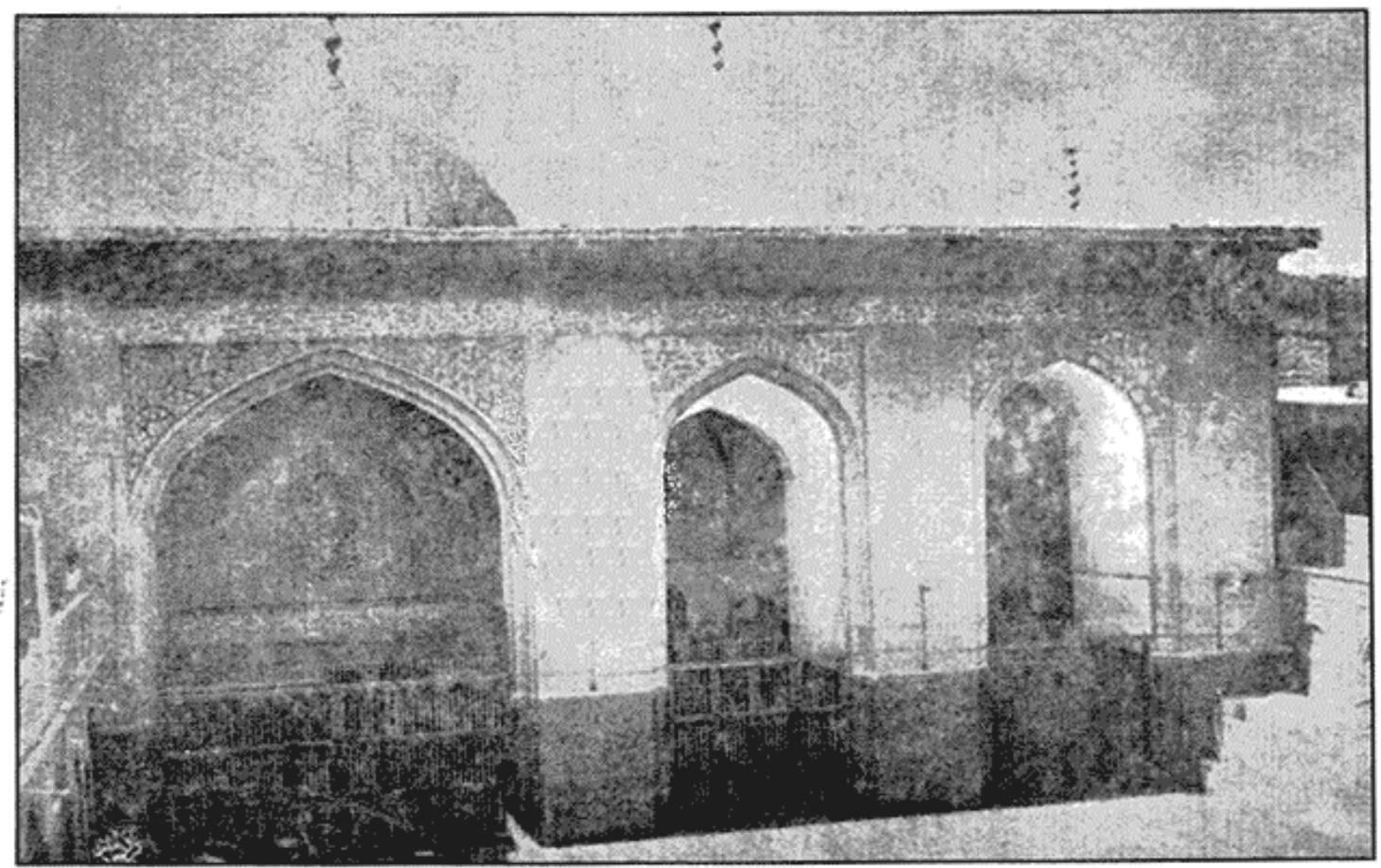

الجبهة الأمامية لجامع سيد سلطان علي ـ دار الآّار العراقية

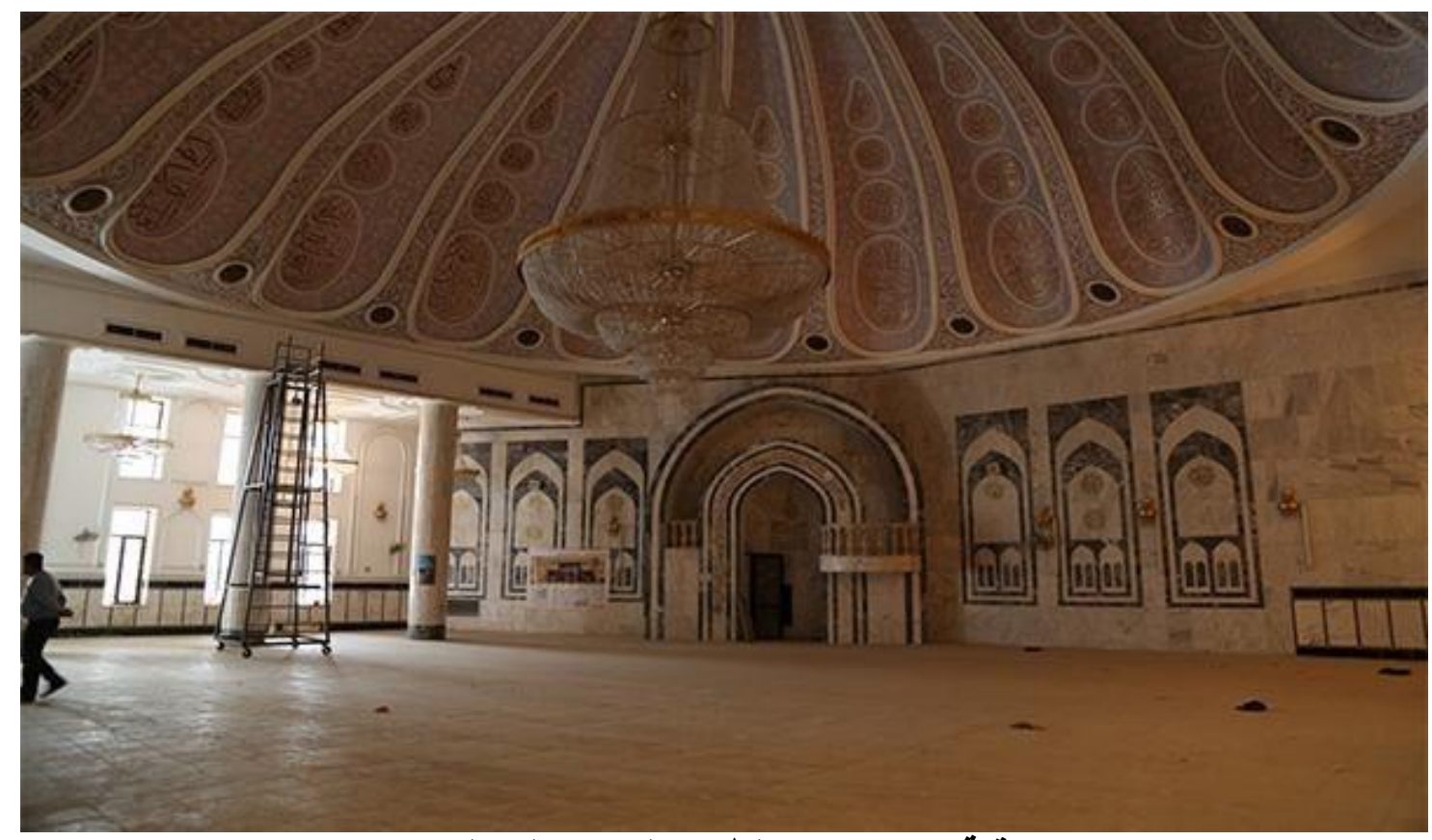

قبة جامع سيد سلطان علي من الداخل 


\begin{tabular}{|c|c|c|c|}
\hline \& bes & 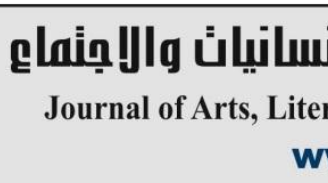 & 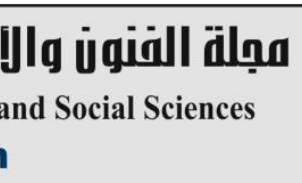 & \\
\hline$==$ & Volume (52) May 2020 & العدد (52) مايو 2020 & \\
\hline
\end{tabular}
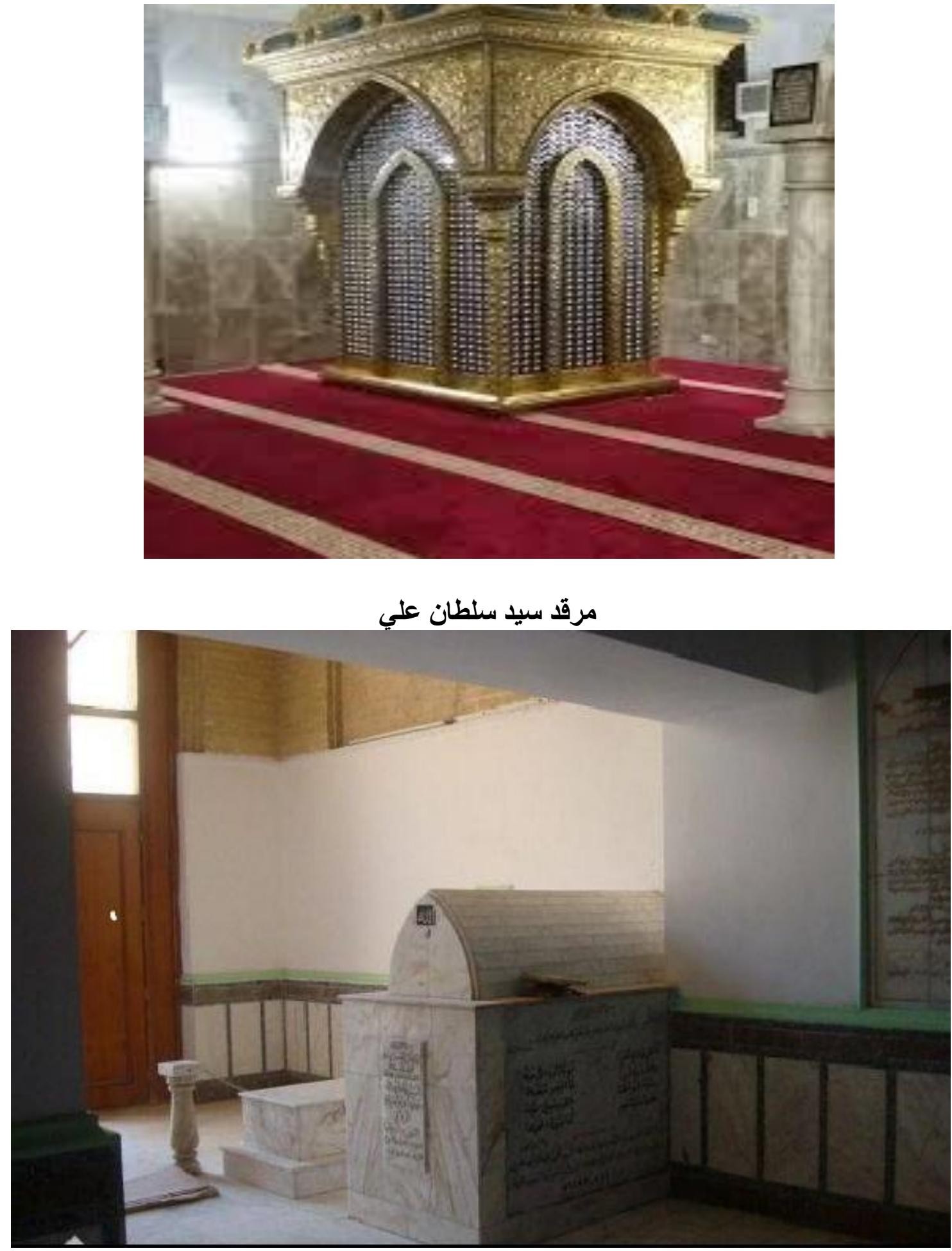

مرقد الامام الرواس في جامع سيد سلطان علي 